\title{
High prevalence of coronary risk factors among bank employees in India
}

Background: Bank employees are considered to have work situation bearing directly on the health status of individual. Materials and Methods: The employees were subjected to a detailed interview, examination and appropriate laboratory investigations. Data analysis was done using the SPSS 11.5. Results: About $50 \%$ of the population had presence of more than, one coronary risk factors. Conclusion: The prevalence of various risk factors for bank employees paralleled the prevalence rates in urban areas as per other studies and hence appropriate counseling and other interventional measures need to be instituted in this vulnerable population, to prevent cardiovascular disease.

Key words: Bank employee, coronary risk factors, diabetes, hypercholesterolemia, hypertension, sedentary lifestyle

\section{INTRODUCTION}

Cardiovascular diseases (CVDs) account for $29 \%$ of the cause of death, globally. ${ }^{[1]}$ In 2005 , there were 16.7 million deaths due to CVD and the figure is projected to rise to 19 million in $2020 .{ }^{[2]}$ The working force of the population belong to 30-59 years age group. This age period is also witness to high incidence of coronary heart disease (CHD) in the population at large..$^{[3]}$ The work environment can enhance the CHD risk. There is a definite and direct link between work situation and health status. ${ }^{[4]}$ The incidence of stroke and CHD is doubled in the age group of 53-60 years of age. ${ }^{[5]}$ Death before retirement age is often attributed to CHD. CHD accounts for $45 \%$ premature male deaths and $18 \%$ in females. Work, with its antecedent stresses and strains increases the risk of CHD. ${ }^{[5]}$ Factors that enhance CHD risk at work include; effort reward model, extremes of temperature, highly alert, vigilant job, decision-making, high responsibility, sudden shift from high risk to low risk job. Shift work, alone, has a propensity to cause CHD. ${ }^{[6]}$ In fact, in the European work force, $18 \%$ of workers are on shift or overtime. ${ }^{[7]}$ About $40 \%$ of the working population work in banking sector. Bank employees are certainly one group to be considered where the work situation would allude to their health status. Our study undertakes the coronary risk assessment in 300 blank employees, so as to quantify the risk and aid to bring out appropriate interventional measures.

Department of Community Medicine, Fr. Muller Medical College, Kankanady, Mangalore -

575 002, Karnataka, India. E-mail: drvinayrao777@gmail.com

\begin{tabular}{|l|}
\hline Access this article online \\
\hline Website: www.ijmedph.org \\
\hline DOI: $10.4103 / 2230-8598.144129$ \\
\hline Quick response code: \\
\hline
\end{tabular}

\section{MATERIALS AND METHODS}

A cross-sectional study using 300 of a total of 1200 bank employees in and around Manipal town, were considered using a purposive sampling. The subjects were interviewed in detail for personal details, lifestyle, 7 item-questionnaire to check knowledge of coronary risk factors followed by complete examination (especially blood pressure [BP], height, weight, hip and waist measurement etc.) and laboratory investigations such as lipid profile and oral glucose tolerance test (OGTT) were done.

Employment status was divided into three grades based on rank and qualification. Knowledge about coronary risk factors was graded as adequate and inadequate. Body mass index (BMI) was used to assess obesity and waist to hip ratio was measured to assess truncal obesity. BP measurement was used along with history to calculate prevalence of hypertension; similarly OGTT was used along with history to find the prevalence of diabetes and impaired glucose tolerance (IGT). ${ }^{[8]}$ A detailed dietary history was taken using the $24 \mathrm{~h}$ dietary recall method. Total daily calorie intake as well as proportion of fat in daily diet was calculated. Data analysis was performed using SPSS Version11.5 IBM Corporation. 


\section{RESULTS AND DISCUSSION}

Of the total 300 subjects, $37 \%$ of men belonged to the age group 45-49 years. More than $35 \%$ of subjects belonged to the Grade II of employment status. 63\% were graduates from the sample and $55 \%$ belongs to the middle socioeconomic status. Only $39.6 \%$ of the sample had correct knowledge about the ill effects of smoking, whereas 39\% know that high fat diet is harmful to the heart. Nearly $32 \%$ men had poor knowledge of coronary risk factors and $60 \%$ of Grade II employees had adequate knowledge of coronary risk factors [Table 1]. There is no significant difference in the knowledge of risk factors with respect to educational qualifications. This could be attributed to the fact that the media and mass communications have effectively brought the message to the masses. ${ }^{[9]}$

Sedentary habits were seen in $33 \%$ of the subjects, obesity in $4.3 \%$, but truncal obesity in $12.7 \%$ of the volunteers. Family history of diabetes is $3.6 \%$, while heart disease is $18.6 \%$. In a study conducted in Trivandrum by Joseph et al. in the year 2000 reported a prevalence of obesity $(B M I \geq 30) 2.3 \%$ among man and 9.2\% among women. ${ }^{[10]}$ Enas $\mathrm{et} \mathrm{al}$. in 1996 observed among Asian Indian physicians, prevalence of obesity among 6.7\% ${ }^{[11]}$ Gupta $e t$ al. reported in $1995,11 \%$ of 2212 subjects had truncal obesity. ${ }^{[12]}$ The prevalence of smoking was $16 \%$, in our study; Chadha et al. 1990 in their study at urban Delhi reported a prevalence of smoking in $36.7 \%$ in males over the age of 24 years. ${ }^{[13]}$ Prevalence of alcohol consumption was $10 \%$ in the bank employees, whereas Joseph et al. reported $34.4 \%$ in Trivandrum city. More than $6 \%$ of the subjects consumed $>30 \%$ of their calories as fats. $59 \%$ of the subjects reported the use of saturated oil as the cooking medium in their home that is, coconut oil, pam oil or ghee. $42 \%$ of the bank employees had hypertension. Gupta et al. in 2002 reported from Rajasthan, a prevalence of hypertension among 38.6\%, between the ages 30 and 59 years. ${ }^{[14]}$

The high prevalence of hypertension among the bank employers in Manipal is conjectured to be due to occupational stress, sedentary lifestyle, dyslipidemias and the use of saturated fats. Dietary patterns of high salt intake and consumption of saturated fats cannot be ruled out. Use of finely grated coconut led to show much dyslipidemia when compared to oils hence, the authors opine that finally grated coconut may also play an important role.

\begin{tabular}{|c|c|c|c|}
\hline $\begin{array}{l}\text { Number of } \\
\text { risk factors }\end{array}$ & $\begin{array}{c}\text { Men } \\
(n=178) \% \\
\end{array}$ & $\begin{array}{c}\text { Women } \\
(n=34) \%\end{array}$ & $\begin{array}{c}\text { Total } \\
(n=212) \%\end{array}$ \\
\hline No risk factor & 7.3 & 8.8 & 7.5 \\
\hline 1 & 11.7 & 23.5 & 13.6 \\
\hline 2 & 16.2 & 29.4 & 18.3 \\
\hline 3 & 19.6 & 20.5 & 19.8 \\
\hline$>3$ & 44.9 & 17.6 & 40.5 \\
\hline
\end{tabular}

$\mathrm{CHD}=$ Coronary heart disease
Of the 300 bank employees examined, only 212 (70.6\%) reported for the investigations viz. Lipid profile and 196 nondiabetic subjects were subjected to the OGTT. The profile of nonrespondents to respondents was not much variable and it hence it can be assumed that the study sample would not make a difference in the overall prevalence of risk factors in the study.

Hypercholestrolemia was observed in $50.7 \%$ of subjects. Elevated low density lipoprotein was seen in $43.8 \%$ low high density lipoprotein we seen in $20.2 \%$ hypertriglyceridemia was seen in $35.8 \%$ Kutty et al. reported that a prevalence of hypercholestrolemia in 70\% of the population in Trivandrum city..$^{[15]}$ Gupta et al. in 1997 reported $21 \%$ of urban Rajasthan has compared with rural. ${ }^{[16]}$ Gopinath et al. in 1990 reported in Delhi in 376 asymptomatic CVD patients, of which $34.9 \%$ had hypercholesterolemia. ${ }^{[17]}$ Reddy KS in 1997 in Delhi showed hypercholesterolemia in 36.8\% of males in urban areas. ${ }^{[18]}$ Among the bank employees, $11.7 \%$ had self-reported diabetes and $8 \%$ was diagnosed as diabetes only after OGTT. Kutty et al. in 2000 reported an overall crude prevalence of diabetics to be $60.8 \%$ in the $30-50$ age group in Trivandrum. ${ }^{[19]}$ Gupta et al. ${ }^{[20]}$ in 1994 reported from Jaipur in $12.27 \%$ diabetes in the 30-59 years age group. Ramachandra et al. showed in 1992 diabetes prevalence in those over 20 years of age to be $8.2 \%$ urban in contrast to $2.4 \%$ in rural areas, while impaired glucose tolerance test was $8.7 \%$ in urban end 7.8 in rural areas. Dowse et al. 1990 in their study reported an age adjusted prevalence of IGT of $16.2 \%$ in adult Indian males. ${ }^{[13]}$

The most frequent risk factor in this study was dyslipidemias, diabetes, less physical activity and truncal obesity. Kamlaker et al. in their study at NIRD, Hyderabad found that at least 1 risk factor in was seen in $26 \%, 2$ risk factors in $5.8 \%$, while $14.5 \%$ had at least 3 or more risk factors. The study undertaken shows there are high prevalence of risk factors in bank employees. Hence, appropriate interventional measures are needed to halt the evolution of CHD in bank employees. To this end, regular health checks, health education, leisure time activity, reduce radiation, bailout stress, use of ergonomic chairs etc., Kutty et al. 2000 reported and overall crude prevalence of diabetics to be $60.8 \%$ in the $39-59$ age group in Trivandrum. ${ }^{[15]}$ Gupta et al. 2002 reported from Jaipur diabetics in $12.27 \%$ separately, in the 30-59 age group [Table 2 and 3].

Ramachandra et al. in 1992 reported in their study at Madras a high prevalence of diabetics. The bank employees in contrast to other sectors of workforce have to contend with a stressful, sedentary lifestyle that accelerates their risk of developing CHD. ${ }^{[17]}$ Stable domestic economics further compound their risk for CHD by reduced physical activity and use of saturated fats. Knowledge of coronary risk factors is itself an effective deterrent that aids prevention of CHD. ${ }^{[21-26]}$

\section{CONCLUSION}

Cardiovascular disease occurs due to work environment as seen in the statistical figures of WHO, where the contributory factors 


\begin{tabular}{lccc}
$\begin{array}{l}\text { Table 2: Prevalence of dyslipidemia among bank } \\
\text { employees }\end{array}$ & $\begin{array}{c}\text { Men } \\
(\boldsymbol{n}=\mathbf{1 7 8}) \\
\mathbf{\%}\end{array}$ & $\begin{array}{c}\text { Women } \\
(\boldsymbol{n}=\mathbf{3 4}) \\
\text { \% }\end{array}$ & $\begin{array}{c}\text { Total } \\
(\boldsymbol{n}=\mathbf{2 1 2}) \\
\text { \% }\end{array}$ \\
\hline Hisk factor & 53 & 38.2 & 20.86 \\
High cholesterol $(>200 \mathrm{mg} / \mathrm{dl})$ & 45 & 38.36 & 43.8 \\
Low HDL cholesterol $(<40 \mathrm{mg} / \mathrm{dl})$ & 22.5 & 8.8 & 20.2 \\
High TC/HC ratio $(>5)$ & 55 & 14.7 & 48.5 \\
High TGL $(200 \mathrm{mg} / \mathrm{dl})$ & 40 & 14.7 & 35.8 \\
\hline
\end{tabular}

$\mathrm{LDL}=$ Low density lipoprotein, $\mathrm{HDL}=$ High density lipoprotein, $\mathrm{HC}=$ High

cholesterol, TC = Total cholesterol, TGL = Triglyceride

\begin{tabular}{lcccc}
\multicolumn{5}{l}{ Table 3: Prevalence of coronary risk factors } \\
\multicolumn{5}{l}{ across various risk factors studies } \\
\hline Risk factor & $\begin{array}{c}\text { Present } \\
\text { study \% }\end{array}$ & $\begin{array}{c}\text { Joseph } \\
\text { et al. } .^{[10]} \%\end{array}$ & $\begin{array}{c}\text { Gupta and } \\
\text { Gupta }{ }^{[0]} \%\end{array}$ & $\begin{array}{c}\text { Singapore } \\
\text { Indians }{ }^{[29]} \%\end{array}$ \\
\hline Male & 82 & 37 & 64 & 47.5 \\
Sedentary habit & 33 & 18 & 71 & 25 \\
Smokers & 15.3 & 24 & 32.3 & 15.3 \\
Drinkers & 13.5 & 17 & 10.3 & NA \\
Obesity & 4.3 & 6.3 & NA & 12.3 \\
Truncal obesity & 19.3 & NA & 21 & NA \\
Hypertension & 47.5 & 37 & 31 & 23.7 \\
IGT & 5.5 & NA & NA & 13 \\
Diabetes & 20.3 & 16.3 & NA & 14.5 \\
High cholesterol & 50.7 & 70 & NA & NA \\
\hline
\end{tabular}

NA = Not available, IGT = Impaired glucose tolerance

are the heavy stress, demand-output, shift and over time work etc. Urbanization itself contributes to $\mathrm{CHD} \cdot{ }^{[27-29]}$ Diabetes mellitus is on the rise and is set to be a "CVD." Pollution as bearing upon the individual risk of developing CHD, environmental influences and genetic factors play a role in evolution of CHD in an individual. Thus the multi factorial causation of CHD is further compounded by the vagaries of one's employment. Hence, our study stands to define into the South Indian region, the humble statistics that has been worked out by many studies. Similar studies would pave a formidable database to propound any theories in the offing. The bank employees form a large sector in the working population. Moreover, there may be preponderance to $\mathrm{CHD}$, in synchrony with all other risk factors affecting the population at large. The prevalence of 2-3 risk factors was quite common and dyslipidemia is the least common denominator for CHD. These findings are in tandem with other studies, conducted in the general population. The section of 30-59 years of the working populace has $40 \%$ working as bank employees or related fields. This study rings out an alarm, to take constructive interventional measures to reduce the inevitable CHD from manifesting in the chair bound occupations.

\section{REFERENCES}

1. Gupta R, Prakash H, Majumdar S, Sharma S, Gupta VP. Prevalence of coronary heart disease and coronary risk factors in an urban population of Rajasthan. Indian Heart J 1995;47:331-8.

2. Chobanian AV, Bakris GL, Black HR, Cushman WC, Green LA, Izzo JL $\mathrm{Jr}$, et al. Seventh report of the Joint National Committee on Prevention,
Detection, Evaluation, and Treatment of High Blood Pressure. Hypertension 2003;42:1206-52.

3. Steenland K, Fine L, Belkic K, Landsbergis P, Schnall P, Baker D, et al. Research findings linking workplace factors to CVD outcomes. Occup Med 2000;15:7-68.

4. Benowitz NL. Cardiotoxicity in the workplace. Occup Med 1992;7:465-78.

5. Harvey WP. Clinical aspects of cardiac tumors. Am J Cardiol 1968;21:328-43.

6. Enas EA. Coronary artery disease epidemic in Indians: A cause for alarm and call for action. J Indian Med Assoc 2000;98:694-5, 697.

7. Dowse GK, Gareeboo H, Alberti KG, Zimmet P, Tuomilehto J, Purran A, et al. Changes in population cholesterol concentrations and other cardiovascular risk factor levels after five years of the non-communicable disease intervention programme in Mauritius. Mauritius Noncommunicable Disease Study Group. BMJ 1995;311:1255-9.

8. Dowse GK, Gareeboo H, Zimmet PZ, Alberti KG, Tuomilehto J, Fareed D, et al. High prevalence of NIDDM and impaired glucose tolerance in Indian, Creole, and Chinese Mauritians. Mauritius noncommunicable disease study group. Diabetes 1990;39:390-6.

9. Gupta R, Gupta VP. Urban-rural differences in coronary risk factors do not fully explain operator urban coronary heart disease prevalence. J Assoc Physicians India 1997;45:683-6.

10. Joseph A, Kutty VR, Soman CR. High risk for coronary heart disease in Thiruvananthapuram city: A study of serum lipids and other risk factors. Indian Heart J 2000;52:29-35.

11. Reddy KS. Cardiovascular disease in India. World Health Stat Q 1993;46:101-7.

12. Gupta R. Changing trends in lipid levels in an urban Indian population. Indian Heart J 2001;53:650-9.

13. Chadha SL. Dietary factors and urban-rural incidence of coronary heart disease. Indian J Nutr Diet 1996;33:145-9.

14. Gupta R, Prakash H, Kaul V. Cholesterol lipoproteins, triglycerides, rural-urban differences and prevalence of dyslipidaemia among males in Rajasthan. J Assoc Physicians India 1997;45:275-9.

15. Kutty VR, Soman CR, Joseph A, Pisharody R, Vijayakumar K. Type 2 diabetes in Southern Kerala: Variation in prevalence among geographic divisions within a region. Natl Med J India 2000;13:287-92.

16. Gopinath N, Kaul U, Chadha SL, Sood AK, Bhattacharya D, Radhakrishnan S. Asymptomatic coronary heart disease detected on epidemiological survey of urban population of Delhi. Indian Heart $\mathrm{J}$ 1992;44:95-8.

17. Ramachandran A, Snehalatha C, Latha E, Manoharan M, Vijay V. Impacts of urbanisation on the lifestyle and on the prevalence of diabetes in native Asian Indian population. Diabetes Res Clin Pract 1999;44:207-13.

18. Kamalakar KV, Jaishanker S, Kumar R, Kapordhi PL, Srinivas BD, Rao S. Study of risk factor profile of coronary artery disease in a community [Abstract]. Indian Heart J 1997;49:617.

19. Kamalkar KV, Jaishanker S, Rajendra KP. Lipid profile in an urban sedentary population - A community based study [Abstract]. Indian Heart J 1997;49:678.

20. Gupta R, Gupta VP, Ahluwalia NS. Educational status, coronary heart disease, and coronary risk factor prevalence in a rural population of India. BMJ 1994;309:1332-6.

21. Pope CA $3^{\text {rd }}$, Burnett RT, Thun MJ, Calle EE, Krewski D, Ito K, et al. Lung cancer, cardiopulmonary mortality, and long-term exposure to fine particulate air pollution. JAMA 2002;287:1132-41.

22. Wilson PW. Diabetes mellitus and coronary heart disease. Am J Kidney Dis 1998;32:S89-100.

23. Pope CA $3^{\text {rd }}$, Burnett RT, Thurston GD, Thun MJ, Calle EE, Krewski D, et al. Cardiovascular mortality and long-term exposure to particulate air pollution: Epidemiological evidence of general pathophysiological pathways of disease. Circulation 2004;109:71-7.

24. Kutty VR, Balakrishnan KG, Jayasree AK, Thomas J. Prevalence of coronary heart disease in the rural population of Thiruvananthapuram district, Kerala, India. Int J Cardiol 1993;39:59-70.

25. Jajoo UN, Kalantri SP, Gupta OP, Jain AP, Gupta K. The prevalence of coronary heart disease in rural population from central India. J Assoc Physicians India 1988;36:689-93.

26. Grundy SM. Small LDL, atherogenic dyslipidemia, and the metabolic syndrome. Circulation 1997;95:1-4. 
27. Byberg L, Siegbahn A, Berglund L, McKeigue P, Reneland R, Lithell H. Plasminogen activator inhibitor-1 activity is independently related to both insulin sensitivity and serum triglycerides in 70-year-old men. Arterioscler Thromb Vasc Biol 1998;18:258-64.

28. Chadha SL, Radhakrishnan S, Ramachandran K, Kaul U, Gopinath N. Epidemiological study of coronary heart disease in urban population of Delhi. Indian J Med Res 1990;92:424-30.

29. Hughes K, Aw TC, Kuperan P, Choo M. Central obesity, insulin resistance, syndrome X, lipoprotein(a), and cardiovascular risk in Indians, Malays, and Chinese in Singapore. J Epidemiol Community Health 1997;51:394-9.

How to cite this article: Rao V, Rao P. High prevalence of coronary risk factors among bank employees in India. Int J Med Public Health 2014;4:500-3.

Source of Support: Nil, Conflict of Interest: None declared. 